\title{
A ONU e a difusão do desenvolvimento sustentável: o caso brasileiro
}

\section{The UN and the diffusion of sustainable development: the Brazilian case}

La ONU y la difusión del desarrollo sostenible: el caso brasileño

\author{
Pascoal Teófilo Carvalho Gonçalves \\ Departamento de Relações Internacionais da Universidade Federal \\ da Paraíba - UFPB CCSA - João Pessoa, Paraíba, Brasil \\ E-mail: pascoal.goncalves@academico.ufpb.br \\ Orcid: https://orcid.org/0000-0002-1336-3148 \\ Bruno Domingos do Nascimento \\ Departamento de Relações Internacionais da Universidade Federal \\ da Paraíba - UFPB CCSA - João Pessoa, Paraíba, Brasil \\ E-mail: bddn@academico.ufpb.br \\ Orcid: https://orcid.org/0000-0002-5441-6103
}

Resumo: $\mathrm{O}$ artigo busca identificar empiricamente o impacto do debate internacional sobre desenvolvimento na agenda governamental brasileira. Objetiva-se aprofundar os estudos sobre o impacto do ambiente internacional na formulação de políticas públicas domesticamente, especificamente lançando luz no processo de formação de agenda governamental face à agenda internacional de desenvolvimento pactuada nos Objetivos de Desenvolvimento Sustentável em 2015. Para tanto, utilizamos análise de conteúdo para pesquisar três macro dimensões do desenvolvimento sustentável - social, ambiental e econômica - nos diários da Câmara dos Deputados do Brasil. Em termos de recorte temporal, definimos os anos de 1992, quando o país sediou a Rio 92, e 2015, quando a Agenda 2030 foi adotada com a definição dos Objetivos de Desenvolvimento Sustentável. A análise dos dados textuais revela um impacto significativo das discussões na ONU no trabalho do legislativo no Brasil.

Palavras-chave: Difusão de Políticas; Desenvolvimento Sustentável; Políticas Públicas. 
Abstract: The article seeks to identify empirically the impact of the international debate on development on the Brazilian government agenda. The objective is to deepen studies on the impact of the international environment on the formulation of public policies at home, specifically shed light on the process of shaping the governmental agenda in view of the international development agenda agreed in the Sustainable Development Goals in 2015. For this purpose, we use analysis of content to research three macro dimensions of sustainable development - social, environmental, and economic - in the newspapers of the Chamber of Deputies of Brazil. In terms of time frame, we defined the years 1992, when the country hosted Rio 92, and 2015, when the 2030 Agenda was adopted with the definition of the Sustainable Development Goals. The analysis of textual data reveals a significant impact of discussions at the UN on the work of the legislature in Brazil.

Keywords: Policy Diffusion; Sustainable development; Public policy.

Resumen: El artículo busca identificar empíricamente el impacto del debate internacional sobre el desarrollo en la agenda del gobierno brasileño. El objetivo es profundizar los estudios sobre el impacto del entorno internacional en la formulación de políticas públicas en el hogar, específicamente arrojar luz sobre el proceso de conformación de la agenda gubernamental en vista de la agenda de desarrollo internacional acordada en los Objetivos de Desarrollo Sostenible en 2015. Por Con este propósito, utilizamos el análisis de contenido para investigar tres macro dimensiones del desarrollo sostenible - social, ambiental y económico - en los periódicos de la Cámara de Diputados de Brasil. En términos de tiempo, definimos los años 1992, cuando el país fue sede de Río 92, y 2015, cuando se adoptó la Agenda 2030 con la definición de los Objetivos de Desarrollo Sostenible. El análisis de datos textuales revela un impacto significativo de las discusiones en la ONU sobre el trabajo de la legislatura en Brasil.

Palabras clave: Difusión de políticas; Desarrollo sostenible; Política pública. 


\section{Introdução}

Em dezembro de 1961 a Assembleia Geral das Nações Unidas designou aquela década como a Década de Desenvolvimento das Nações Unidas, na qual os Estados membros, fossem eles países desenvolvidos ou em desenvolvimento, bem como suas respectivas populações, deveriam intensificar os esforços para acelerar o progresso econômico e o avanço social, definindo a meta de crescimento econômico para os países em desenvolvimento na ordem de $5 \%$ ao ano até 1970 .

Desde os anos de 1960 o debate sobre desenvolvimento internacional no âmbito do sistema ONU produziu ideias e conceitos que são difundidos pelo mundo e se tornam parâmetro para a definição de políticas por parte dos tomadores de decisão. Como lembra Santos Filho (2005), num primeiro momento, as noções e modelos de progresso e modernização foram diluídas nas iniciativas de "ajuda para o desenvolvimento" que pautaram as relações cooperativas internacionais Norte-Sul no pós-Guerra. As metas de crescimento, as estratégias para alcançar os objetivos e as agendas temáticas a serem priorizadas foram acompanhando, progressivamente desde os anos de 1960, a conjuntura internacional e o debate acadêmico sobre desenvolvimento, transformando a natureza da cooperação internacional e, principalmente, as noções de desenvolvimento difundidas a partir da ONU.

Essas orientações para o desenvolvimento, expressas nas inúmeras resoluções aprovadas em quase sessenta anos de debate, implicam em deliberações oficiais que os tomadores de decisões nos Estados se valerão para traçar planos, metas e, em última instância, criarem suas percepções objetivas e subjetivas sobre a natureza dos problemas e das soluções públicas relacionadas ao desenvolvimento. Tendo isso em mente, podemos dizer que a ONU serve como um importante ator para a difusão de políticas, seja do ponto de vista objetivo (metas e estratégias), seja do ponto de vista subjacente (o que é desenvolvimento e como alcançá-lo).

O fenômeno da difusão internacional de políticas públicas tem chamado a atenção da comunidade científica há décadas e gerou uma farta e fragmentada literatura (GRAHAM; SHIPAN; VOLDEN, 2013). Acompanhando o interesse da comunidade acadêmica sobre o tema, a internacionalização dos processos de produção das políticas públicas, tanto nos governos 
centrais como nos subnacionais se tornou um fenômeno perceptível em todas as etapas do ciclo das políticas públicas (FARIA, 2018). O presente artigo tem por objetivo geral aprofundar os estudos sobre o impacto do ambiente internacional da formulação de políticas públicas domesticamente, especificamente lançando luz no processo de formação de agenda governamental no Brasil face à agenda internacional de desenvolvimento pactuada nos Objetivos de Desenvolvimento Sustentável em 2015.

Dentre as abordagens teóricas sobre o processo de difusão, o institucionalismo sociológico e algumas de suas vertentes chamam a atenção para os constrangimentos sociais sobre a tomada de decisão dos atores políticos e a forma pela qual um repertório de questões e respostas são socialmente definidas a priori, cognitivamente, atrás do escopo de visão objetiva dos atores. Assim, tomadores de decisão emulam aquilo que está sendo feito em outros lugares, legitimando ideias e ações com aquilo que é tido como "normal".

A partir desse referencial, podemos pensar na agenda governamental como uma série de questões que eventualmente se tornam o foco da atenção dos tomadores de decisão pelo fato de que, em muitos outros lugares, também essas questões passaram ao centro da agenda (KINGDON, 2014). Nesse sentido, cabe indagarmos sobre os atores e processos envolvidos na naturalização de determinadas questões na agenda governamental de um país que surgiram ou foram definidas em outro lugar.

Todavia, para lançar luz sobre a formação da agenda pública no Brasil, devemos ter em mente o papel das Organizações Internacionais (Ols). Conforme veremos, as Ols podem impactar as políticas públicas de diversas formas; neste artigo, tomaremos como referência a capacidade de definir e difundir normas internacionais que delimitam cognitivamente os atores públicos. Tendo isso em mente, nosso problema de pesquisa é: há evidências empíricas da difusão de normas das organizações internacionais para o Brasil?

Nosso trabalho busca responder essa questão a partir da literatura já publicada sobre o tema e pela análise dos diários da Câmara dos Deputados do Brasil. Partimos da noção de que Ols definem e difundem normas internacionais, constrangem ideias sobre os problemas e suas soluções, colocando novas ideias e conceitos na agenda governamental. Apesar de a literatura apontar a resposta para nosso problema, buscamos também evidências empíricas que deem 
sustentação à literatura. Para tanto, tomamos como caso o impacto da ONU na Câmara dos Deputados do Brasil. Como dito, dois momentos foram utilizados como parâmetros: o ano de 1992, quando aconteceu a Conferência das Nações Unidas sobre Meio Ambiente e Desenvolvimento, conhecida como Rio 1992, e o ano de 2015, quando, na 70a Assembleia Geral da ONU, os Objetivos de Desenvolvimento Sustentável foram adotados.

Nesse sentido, a escolha dos dois momentos históricos se justifica por: 1) 1992 é tido como o ano no qual o conceito de desenvolvimento sustentável se torna um termo chave no debate sobre desenvolvimento; 2) o intervalo de quase 25 anos é tempo suficiente para ocorrerem mudanças na concepção dos atores, no caso, os membros do legislativo brasileiro; 3) os dois anos marcam o início do processo de mudança no debate internacional sobre desenvolvimento e seu, até então, último capítulo. Tendo isso em mente, definimos o corpus textual do presente trabalho como sendo todos os diários da Câmara dos Deputados do Brasil dos anos de 1992 e 2015, num total de 448 documentos oficiais.

A análise do corpus foi feita por meio de análise de conteúdo, de forma dedutiva, ou seja, a partir da literatura sobre desenvolvimento sustentável foi criado um codebook com os principais termos a serem buscados de forma automatizada nos documentos. Os termos dizem respeito às seguintes categorias: economia, política social, meio ambiente e sustentabilidade.

Apesar de o problema de pesquisa sugerir teste de hipótese, nossa análise qualitativa versará, em consonância com Kelle (2015), sobre exame de hipótese. Sustentamos que há relação entre o debate internacional no âmbito das Ols e que essa relação pode ser, sim, demonstrada empiricamente por meio de análise de conteúdo. Conforme detalhado mais adiante, partimos da seguinte proposição: se as categorias do nosso estudo - economia, política social e meio ambiente - co-ocorrem com a categoria "sustentabilidade", então teremos as nossas dimensões de análise: sustentabilidade econômica; sustentabilidade social; e sustentabilidade ambiental.

Desenvolvimento sustentável, em suas dimensões econômica, social e ambiental, é um termo derivado do debate internacional sobre desenvolvimento. Logo, se um termo que surge no âmbito das Ols chega aos trabalhos parlamentares no Brasil, a hipótese de que há difusão 
de normas das Ols para a arena doméstica ganha elementos empíricos. Nesse sentido, e definidas as dimensões do nosso estudo, podemos analisar nossa hipótese da seguinte forma: sendo nossa hipótese válida, variações em uma ou mais dimensões serão observadas no período de realização das conferências.

O artigo está organizado em quatro seções, para além desta introdução e da conclusão: inicialmente revisamos os conceitos de difusão e transferência internacional de políticas públicas. Essa revisão permite localizar nosso trabalho teoricamente nos estudos decorrentes do institucionalismo sociológico. Posteriormente, passamos para uma discussão sobre o papel das Organizações Internacionais e seu impacto nas políticas públicas domésticas. Em seguida, apresentamos o processo de consolidação do conceito de desenvolvimento sustentável no debate internacional. A quarta parte apresenta de forma pormenorizada a metodologia do trabalho e os principais resultados, quais sejam, a análise de conteúdo conduzida com auxílio do software Atlas.ti encontrou elementos que sugerem uma relação próxima entre as discussões na ONU e o trabalho do legislativo no Brasil.

\section{Difusão e transferência internacional de políticas públicas}

A presente seção tem por objetivo discutir sinteticamente a seguinte questão: como ocorre o processo de difusão internacional de políticas e, principalmente, ideias? Para responder essa questão devemos ter em mente os conceitos de difusão/transferência de políticas públicas e o papel das ideias nas abordagens sociológicas/organizacionais.

A literatura sobre difusão que se volta para a origem exógena de determinadas políticas públicas possui dois grandes eixos analíticos: transferência e difusão de políticas. Segundo Newmark (2002), difusão é um termo mais geral, que pode englobar fatores estruturais na explicação sobre a adoção de uma determinada política. Por outro lado, a transferência é mais específica e diz respeito aos casos de conhecimento consciente de uma política, programa ou ideia que é utilizado no desenvolvimento de uma política domesticamente. Apesar das possibilidades de contribuição recíproca (FARIA, 2003, 2018; MARSH; SHARMAN, 2009), os estudos ainda seguem caminhos diferentes: enquanto os estudos sobre transferência de políticas focam nos mecanismos e atores, dando preferência 
para abordagens metodológicas como o process-tracing; as pesquisas sobre difusão, em sua busca de compreensão sobre a estrutura, possuem uma orientação teórica mais bem desenvolvida e preferência por metodologias quantitativas por conta de sua capacidade de análise macro (BENNETT, 1991; BENNETT; HOWLETT, 1992; BENSON; JORDAN, 2011; DOLOWITZ; MARSH, 2000). Nosso trabalho se insere nos estudos sobre difusão de políticas.

Quando analisamos a literatura sobre difusão, nos deparamos com aquilo que Braun e Gilardi (2006) identificaram como a ausência de uma estrutura teórica coerente. Todavia, apesar da ausência de uma coerência teórica, Dobbin, Simmnons e Garret (2007) identificam quatro diferentes matrizes que contribuem com a difusão: construção social, coerção, competição e aprendizado. A coerção ocorre quando uma política é imposta por uma organização internacional ou país poderoso (FMI, Banco Mundial e UE), se valendo de ameaças, como imposição de sanções, ou prometendo ajuda em troca de proteção fiscal, livrecomércio, etc. (DOBBIN; SIMMONS; GARRETT, 2007).

A competição ocorre quando países influenciam uns aos outros em busca de recursos econômicos (GILARDI, 2013). Países competem para atrair investimento e vender exportações, reduzindo o custo de fazer negócios, reduzindo as restrições ao investimento ou reduzindo as barreiras tarifárias na esperança de reciprocidade (DOBBIN; SIMMONS; GARRETT, 2007). Esse processo geralmente é orientado por preceitos liberais e implica na redução do peso do Estado na economia, desregulamentação financeira e retração na oferta de políticas sociais. Esse tipo de competição é conhecido pelo termo "race to the botton" (FARIA, 2018).

O aprendizado diz respeito a experiências de outros países em prover informações úteis sobre as consequências de uma política. Para Dolowitz e Marsh (1996), há aprendizado (lesson drawing), quando atores políticos em um país aprendem com outras experiências de outros lugares. Como ressalta Faria (2018), é possível aprender também com a própria experiência, de forma que novas evidências alterem as crenças prevalecentes sobre a relação causa-efeito esperada de uma dada estratégia de intervenção governamental.

Por fim, o construtivismo entende que as normas políticas são organizadas em comunidades epistêmicas e Organizações Internacionais, que definem noções como 
progresso e direitos humanos. Nessa perspectiva, alinhada com o neo institucionalismo sociológico e organizacional, organizações emulam umas às outras buscando legitimidade, levando a um crescente isomorfismo. Isso se dá por que características normativas e socialmente construídas de políticas importam mais que suas consequências objetivas, levando a uma padronização de políticas e organizações dentro e entre diferentes ambientes (GILARDI, 2013; MEYER; ROWAN, 1977).

Landolt (2004) aponta que os construtivistas enfatizam a construção tanto da estrutura social como da agência dos atores e dão ênfase ao papel das ideias e normas em (re)definir os interesses e objetivos dos Estados ao longo do tempo. A abordagem construtivista assume que as normas ocidentais, como a racionalidade, a democracia liberal, os mercados livres, os direitos humanos e o próprio Estado (enquanto única forma legitima de organização política nas relações internacionais) se difundem internacionalmente por meio de uma estrutura social internacional independente, em vez de serem projetadas a partir do nível doméstico. Decorre disso que, nessa abordagem, as Organizações Internacionais têm um papel de destaque (FINNEMORE, 1996; LANDOLT, 2004). Daremos mais de atenção e profundidade à perspectiva sociológica da difusão internacional na seção a seguir.

\section{A difusão internacional de normas e ideias e as políticas públicas}

A difusão internacional de políticas públicas pode decorrer de mudanças nas ideias, numa perspectiva construtivista, ou nos incentivos dos atores, numa leitura coercitiva. A vertente construtivista sociológica que subsidia este artigo sustenta que mudanças nas ideias levam a mudanças nas políticas, enfatizando o poder das teorias e da retórica como fontes de novas ideias (DOBBIN; SIMMONS; GARRETT, 2007)

Para Campbell (1998), os insights centrais do institucionalismo organizacional para entendermos o papel das ideias nas políticas públicas são sua teoria de restrição que foca em estruturas subjacentes cognitivas, ao invés das estruturas normativas, e sua teoria da ação, que descreve como os atores definem e articulam seus problemas políticos e soluções inicialmente utilizando seus scripts institucionalizados, e rotinas que constituem suas estruturas cognitivas, capacitando-os a agir. Nesse sentido, as ideias podem ser pressupostos 
subjacentes, quando são tomadas como dadas no contexto do debate sobre políticas ou então podem ser cognitivas, enquanto descrições e análises teóricas que especificam relações de causa e efeito. Ideias fornecem, assim, soluções específicas para problemas políticos, constrangem o escopo cognitivo das soluções que os formuladores de políticas estão dispostos a considerar e constituem símbolos e conceitos que permitem que os atores construam estruturas com as quais legitimam as propostas de políticas.

A teoria da ação na perspectiva sociológica deve muito à obra de Giddens (2018), e sua discussão sobre agência, estrutura e estruturação. Sinteticamente, a estruturação parte do suposto herdado dos estruturalistas da sociolinguística (Saussure, Derrida e, principalmente Lévi-Strauss) de que a conduta humana depende em grande medida de "estruturas gerativas", como a linguagem e outras instituições sociais. Todavia, Giddens pensa essas estruturas a partir do teorema da "dualidade" que a estrutura mantém com a agência: se as estruturas fornecem as condições da ação, é mediante a ação que elas são continuamente reconstruídas no tempo-espaço e, assim, se reproduzem historicamente.

Nas palavras do autor,

O conceito de estruturação envolve o de dualidade da estrutura, que está ligado ao caráter fundamentalmente recorrente da vida social e expressa a mútua dependência entre estrutura e atuação. Por dualidade de estrutura entendo que as propriedades estruturais dos sistemas sociais são tanto meios quanto resultado das práticas que constituem esses sistemas. [...] A estrutura, portanto, não deve ser concebida como uma barreira à ação, mas como essencialmente envolvida na sua produção, mesmo nos processos mais radicais de mudança social, que, como quaisquer outros ocorrem no tempo. [...] De acordo com a noção de dualidade da estrutura, regras e recursos são utilizados pelos atores na produção da interação, mas são assim também reconstituídos através dessa interação (GIDDENS, 2018, p. 78-79).

Conforme argumenta Campbell (1998), as estruturas sociais "possibilitam" e "empoderam" os atores a gerarem soluções para seus problemas provendo pistas e scripts sobre as formas legítimas de ação. A teoria da ação reconhece a importância da agência, uma vez que reconhece que atores autoconscientes inventam soluções para seus problemas pela manipulação explícita e deliberada de conceitos culturalmente dados (estrutura) no primeiro plano cognitivo. 
Segundo Dobbin, Simmons e Garrett (2007), o entendimento de como as políticas públicas se tornam socialmente aceitas é fundamental para entender por que elas são difundidas internacionalmente. Entender como determinadas políticas começam a ser seguidas, ou posições defendidas em determinados países ou organizações internacionais, passa necessariamente pelo entendimento de quais são as formas legitimadas de percepção de problemas e soluções num dado momento do tempo. A aceitação e, por conseguinte, legitimação de uma política pode se dar por três caminhos: países líderes servem como exemplo e outros países passam a imitar considerando que, aparentemente, estão fazendo a coisa certa (siga o líder); especialistas levantam argumentos sobre a adequação de uma política, definindo-a como a certa em determinadas circunstâncias.

A terceira forma de legitimação de uma política é por meio grupos de especialistas que teorizam sobre os efeitos de uma nova política, dando aos formuladores razões para adotálas (aprendizado racional). Isso diz respeito mais a um isomorfismo normativo que um "case de sucesso" em particular. Aqui cabe indagar qual grupo tem capacidade de estabelecer o isomorfismo normativo nessa magnitude. Dobbin, Simmons e Garrett (2007) sustentam que as Organizações Internacionais têm essa capacidade. A ideia é que mudanças nas ideias impulsionam a difusão de políticas.

O isomorfismo institucional, decorrente do processo de difusão, é abordado na literatura a partir do conceito de convergência política, que trata do efeito da difusão. Bennett (1991) definiu convergência política em termos de: objetivos políticos - uma junção de intenções para lidar com problemas políticos comuns; conteúdo político - as manifestações mais formais da política governamental em termos de estatutos, regras administrativas, regulações, decisões de cortes, etc.; instrumentos políticos - ferramentas institucionais (regulamentares, administrativas ou judiciais) disponíveis para a administrar a política; resultados, impactos ou consequências da implementação da política, sejam positivos ou negativo, eficazes ou ineficazes; convergência de estilo de política - respostas formuladas para responder aos problemas públicos.

Faria (2018) lembra que as Organizações Internacionais não se limitam a ser apenas instrumentos de países poderosos ou simplesmente arenas deliberativas para os Estados. Elas, 
de fato, adquiriram grande capacidade de agência, assumindo protagonismo no processo de internacionalização das políticas. Cabe lembrar que as Ols que têm atuação setorial e/ou estruturante, aumentaram muito em número nas últimas décadas (contribuindo para a institucionalização das relações internacionais), possuem alcance regional/global e são centrais para a construção, legitimação e operação de diversas redes transnacionais e comunidades epistêmicas.

Segundo Jakobi (2009), um dos instrumentos das Ols para influenciar as políticas públicas é a disseminação discursiva, que implica em estabelecer ideias na agenda política nacional. Essa noção está relacionada aos meios que o Estado possui para informar e orientar as escolhas dos cidadãos, mas inclui regras e suposições implícitas sobre como os problemas políticos devem ser resolvidos. Ideias sobre relações de causa e efeito, o impacto das decisões políticas e a ligação com o os objetivos já definidos das políticas são pré-condições importantes para a definição de agendas.

Por que alguns problemas se tornam importantes para um governo? Como uma ideia se insere no conjunto de preocupações dos formuladores de políticas, transformando-se em uma política pública? Essas questões, levantadas por Kingdon (2014) em seu livro clássico sobre mudanças de agenda, estão totalmente alinhadas com nossa discussão. $\mathrm{O}$ autor considera as políticas públicas como um conjunto formado por quatro processos que compreendem: o estabelecimento de uma agenda de políticas; a especificação de alternativas a partir das quais as escolhas vão ser realizadas; a escolha entre o conjunto de alternativas disponíveis e, finalmente, a implementação da decisão. Em seu modelo de multiple streams, o autor se preocupa especificamente com os dois primeiros processos, chamados estágios pré-decisórios: a formação da agenda (agenda-setting) e a especificação de alternativas (policy formulation). A formação da agenda é definida a partir de três fluxos, a saber: o dos problemas; o processo político; e o dos participantes visíveis.

A literatura que examinamos até aqui nos permite sustentar que, em consonância com a obra de Kingdon (2014), o debate internacional no âmbito da ONU sobre desenvolvimento sustentável impacta principalmente a definição dos problemas. Resumidamente, os atores públicos, incluindo Legislativo e Executivo, concentram sua atenção em alguns problemas 
potenciais e ignoraram outros. A vida política dos países é permeada de condições, ou seja, uma situação social percebida, mas que não desperta necessariamente uma ação em contrapartida. Estas condições se tornam problemas apenas quando os formuladores de políticas acreditam que devem fazer algo a respeito (KINGDON, 2014). No caso sobre o debate internacional, os limites físicos do planeta que levaram ao conceito de "desenvolvimento sustentável" progressivamente se tornaram um problema para os tomadores de decisão no nível doméstico dos países.

Cabe então indagar: como estudar o impacto de normas e ideias desenvolvidas internamente na política doméstica? Para responder essa indagação, recorremos a Cortell \& Davis (2000) que defendem que podemos estudar essa relação do internacional para o nacional a partir da saliência doméstica das normas internacionais. Especificamente, os autores apontam que o impacto doméstico pode ser observado em três níveis diferentes, sucessivos e complementares: primeiro, a norma internacional se apresenta no discurso das autoridades políticas; segundo, a norma causa uma mudança institucional doméstica; terceiro, políticas públicas específicas serão criadas em consonância com a norma internacional. Especificamente, nosso trabalho foca no primeiro nível, em diálogo direto com a visão de Jakobi (2009) e Cambell (1998): analisar o impacto das diferentes conferências da ONU nos discursos das autoridades públicas, especificamente na Câmara dos Deputados do Brasil. Assumimos neste artigo que o conceito de normas internacionais é equivalente ao de ideias (na literatura sobre difusão de políticas) ${ }^{1}$.

A próxima seção tem por objetivo apresentar o processo de consolidação do conceito de desenvolvimento sustentável no debate internacional. Implícita nessa seção está a noção de que esse processo de décadas criou um entendimento compartilhado internacionalmente entre especialistas e autoridades sobre os rumos que o desenvolvimento deveria tomar. Esse entendimento compartilhado é parte daquilo que foi identificado anteriormente como

\footnotetext{
${ }^{1}$ Apesar de usarmos os termos de forma intercambiável, cabe ressaltar que normas são mais amplas e constrangem as ideias dos atores políticos. Ver o trabalho clássico de Finnemore e Sikkink (1998) para uma discussão mais detalhada.
} 
"estrutura", e gera, entre seus efeitos, mudanças nos interesses e constrangimentos cognitivos sobre a natureza dos problemas e suas soluções nos atores.

\section{Sustentabilidade e desenvolvimento}

Uma busca por notícias sobre desenvolvimento sustentável na base ProQuest retorna um dado interessante: a primeira vez que o termo surge é em dezembro 1988, numa postagem da "UN Chronicle" que informa sobre um encontro de cúpula das principais agências da ONU para promover o desenvolvimento econômico ambientalmente sustentável, promovido pela então primeira-ministra da Noruega, Gro Harlem Brundtland. As notícias seguintes, uma em 1990, treze em 1991 e trinta e nove notícias em 1992, dão conta da crescente importância do tema e de sua eminente origem no debate internacional sobre desenvolvimento. Conforme apresentado abaixo, a revisão de literatura sobre as origens do uso contemporâneo do termo "desenvolvimento sustentável" embasa a rápida observação dos resultados da busca na ProQuest.

Nos anos de 1960 e 1980, duas correntes no debate ambientalista debateram o termo "sustentabilidade": uma posição utilitarista e outra mais espiritualista. A posição utilitarista defendia a proteção de áreas naturais a partir de uma postura "conservacionista". Contudo, essa postura assumia a forma de um auto interesse iluminado, visando a conservação da terra e demais recursos para posterior uso humano. Decorrente da lógica utilitarista, essa posição tinha como objetivo garantir o maior benefício para a maior parte dos membros de uma sociedade. Por outro lado, a corrente espiritualista defendia a preservação de áreas naturais no que era percebido como sendo sua forma intocada, primitiva, não desenvolvida. Essa posição "preservacionista" era geralmente expressa em termos românticos ou espirituais, remetendo ao transcendentalismo americano e ao romancismo europeu (ROBINSON, 2004).

Essas duas posturas marcaram posições políticas distintas no plano doméstico e no internacional. Paterson (PATERSON, 2001) identifica que os chamados "ambientalistas" no plano político assumiram a postura utilitária, enquanto que os "verdes" defendiam uma mudança social profunda para evitar a crise ambiental. No debate sobre as relações internacionais, os ambientalistas defenderam uma resposta do sistema estatal aos problemas 
ambientais, focando na criação de "regimes ambientais internacionais", numa perspectiva análoga a dos institucionalistas liberais. Os "verdes", por sua vez, identificavam que a raiz da crise ambiental estava nas estruturas políticas, sociais, econômicas e normativas da política mundial, sendo necessários uma guinada ética da humanidade (do antropocentrismo para o ecocentrismo), o reconhecimento dos limites para o crescimento econômico e uma descentralização radical de poder.

O relatório encomendado pelo Clube de Roma e publicado em 1972 com o título "Os limites do Crescimento" lançou muitas das questões que balizaram posteriormente o conceito de "desenvolvimento sustentável". Ao apontar que a Terra tinha um limite físico de recursos e que exceder esse limite de exploração poderia terminar em catástrofe, o relatório convergiu a discussão já existente sobre os impactos ambientais da atividade humana (a agenda ambiental) com a discussão internacional sobre desenvolvimento. Embora parta do reconhecimento dos limites para o crescimento, ponto defendido pelos verdes, o relatório explicita a busca por um modelo de desenvolvimento que tivesse abrangência planetária e que fosse: 1) sustentável sem um colapso súbito e incontrolável da espécie humana; e 2) capaz de satisfazer as necessidades materiais de todas as pessoas (GROBER, 2014).

O termo "desenvolvimento sustentável", em sua acepção contemporânea, foi definido no famoso Relatório "Nosso Futuro Comum", elaborado pela Comissão Brundtland de 1987. Segundo Du Pisani (2006), o Relatório expressou a crença que a igualdade social, o crescimento econômico e a manutenção ambiental são possíveis simultaneamente, assim enfatizando três componentes fundamentais do desenvolvimento sustentável: o meio ambiente, a economia, e a sociedade. Entretanto, apesar de reconhecer a tensão entre crescimento econômico e proteção ambiental, o relatório defendeu que crescimento econômico é fundamental para os países em desenvolvimento, embora um modelo de crescimento econômico ambientalmente sustentável fosse necessário e ainda inexistente.

Pensado a partir da dicotomia conservação/preservação apresentadas anteriormente, o relatório possui notável perspectiva preservacionista/desenvolvimentista. A sustentabilidade ambiental não pode ser alcançada se o problema da pobreza não puder ser efetivamente resolvido globalmente. Desenvolvimento humano, pobreza e deterioração 
ambiental são questões que podem ser resolvidas simultaneamente e de forma que se reforcem mutuamente. Além disso, a resposta para os problemas de super e subconsumo, assim como para as preocupações ambientais, estaria em prover mais desenvolvimento humano. Para tanto, a Comissão Brundtland chega a defender um aumento de 5 a 10 vezes na atividade industrial bruta no mundo ao longo do século XXI para atender às necessidades dos mais pobres. Não há referência ou ênfase em mudança de valores, mudanças na percepção sobre a natureza ou responsabilidade individual. O foco é todo direcionado a respostas institucionais coletivas, ganhos de eficiência e responsabilidade social (ROBINSON, 2004).

Por outro lado, o super-desenvolvimento é uma ameaça equivalente, então mais do mesmo tipo de desenvolvimento não é a resposta. A resposta seria uma nova forma de desenvolvimento sustentável, definido como o desenvolvimento que atende as demandas das gerações atuais sem comprometer a capacidade de futuras gerações em atender suas próprias necessidades (BRUNDTLAND et al., 1987; ROBINSON, 2004).

Segundo Grober (2015), os elementos presentes nessa definição de desenvolvimento sustentável são bastante precisos. Primeiro, o termo "necessidades" é especificado como "necessidades essenciais", ou a satisfação de necessidades básicas. Desenvolvimento é, assim, entendido no contexto de luta contra a pobreza, de justiça Norte-Sul. Ainda, o relatório enfatiza que a capacidade presente e futura do ecossistema de suportar a atividade humana deve definir os limites para a tecnologia e para a civilização. Essa capacidade de suportar se torna então o parâmetro para atividade econômica, e não os mercados globalizados.

A definição do Relatório Brundtland foi transmitida para a Conferência das Nações Unidas sobre o Meio Ambiente e o Desenvolvimento (UNCED em inglês), que ocorreu em 1992 no Rio de Janeiro. Desde então, conforme ressaltado por Grober (2015), sustentabilidade se tornou um termo chave no vocabulário global no século XXI. A Eco-92 também definiu os rumos do regime ambiental, consolidando a preocupação com as mudanças climáticas e definindo a estrutura da ONU para tratar especificamente essa temática: a Convenção-Quadro das Nações Unidas sobre a Mudança do Clima (UNFCC em inglês). 
Segundo Waters (2008), a declaração da Rio 92 conclamou por parcerias globais e novos níveis de cooperação entre Estados, setores chaves da sociedade e indivíduos a fim de estabelecer acordos internacionais pautados pelo respeito aos interesses de todas as partes e que protegessem a integridade do meio ambiente e dos sistemas de desenvolvimento. Líderes de 179 governos assinaram a Agenda 21, o plano de ações definido na Rio 92. As conferências subsequentes da UNCED em 1997, em Nova lorque (EUA) e em 2002, em Johanesburgo (África do Sul) reafirmaram a determinação de muitos países e da ONU em alcançar o desenvolvimento sustentável no século XXI.

Paralelamente, nesse mesmo período, ocorriam as discussões sobre a Estratégia Internacional de Desenvolvimento para a Quarta Década de Desenvolvimento (1991-2000) da ONU, particularmente importante para entendermos como o debate internacional chegou aos Objetivos de Desenvolvimento Sustentável. As Décadas de Desenvolvimento tiveram início nos anos de 1960 e foram marcadas pela atenção ao crescimento econômico pautado em políticas keynesianas para os países em desenvolvimento. Com o passar das décadas, as conferências incluíram progressivamente a complexificação da agenda internacional de desenvolvimento, passando a incluir, por exemplo, os objetivos sociais (emprego, educação, saúde, nutrição, participação) na segunda década e a questão ecológica (mecanismos de gestão e financiamento ecológico) na terceira década.

A Quarta Década de Desenvolvimento se caracterizou pela incorporação da ideia de direitos humanos. Nesse período, os temas sociais assumiram definitivamente o protagonismo em detrimento do enfoque puramente econômico. Refletindo as discussões em outras agendas, a declaração final ressaltou os compromissos de: acelerar o crescimento econômico nos países em desenvolvimento; conceber um processo de desenvolvimento que atendesse às necessidades sociais, reduzindo a extrema pobreza significativamente e que fosse ambientalmente saudável e sustentável; melhorar os sistemas internacionais monetário, financeiro e comercial; fortalecer e estabilizar a economia mundial estabelecendo práticas saudáveis de gestão macroeconômica, tanto nacional como internacionalmente (KOEHLER, 2016). 
Para ilustrar como as outras agendas impactaram nas discussões internas da Quarta Década para o Desenvolvimento, lembramos que os anos 90 ficaram conhecidos como a década das Conferências das Nações Unidas: em 1990, em Nova lorque, sobre a infância; em 1992, no Rio de Janeiro, sobre o meio ambiente e desenvolvimento; em 1993, em Viena, sobre direitos humanos; em 1994, no Cairo, sobre população e desenvolvimento; em 1995, em Pequim, sobre mulheres e desenvolvimento; em 1995, em Copenhague, sobre desenvolvimento social; em 1996, em Roma, sobre segurança alimentar e em Istambul, sobre assentamentos humanos. Ainda, a partir de 1995 começam as Conferências das Partes (COPs) sobre as mudanças climáticas com periodicidade anual (KOEHLER, 2015).

Os Objetivos de Desenvolvimento do Milênio podem ser pensados como o lançamento da quinta Década de Desenvolvimento da ONU. Na linha das décadas anteriores, os ODM definiram objetivos, cronogramas e delimitaram áreas prioritárias de desenvolvimento para as arenas nacionais e internacional. Todavia, os ODM foram além das décadas anteriores ao destrinchar objetivos em metas e oferecer indicadores para mensurar a implementação (KOEHLER, 2016). Os ODM foram adotados no ano 2000 com prazo de 15 anos para sua implementação.

Apesar de os ODMs terem se caracterizado pela timidez em relação aos direitos sociais e humanos, a Agenda de Desenvolvimento do Milênio (2000-2015) teve o mérito de conseguir organizar dezenas de indicadores desenvolvidos para acompanhar a implementação dos ODMs, bem como um grande inventário de políticas e ações bem sucedidas ao redor do globo (JANNUZZI; DE CARLO, 2019). A conferência Rio +20 (Conferência das Nações Unidas sobre Desenvolvimento Sustentável), realizada em 2012, definiu os rumos da agenda internacional de desenvolvimento para o pós-ODM. Foi definido que os novos objetivos de desenvolvimento deveriam almejar e incorporar de forma equilibrada três dimensões fundamentais da sustentabilidade: econômica, social e ambiental (KANIE et al., 2014).

Os Objetivos de Desenvolvimento Sustentável foram aprovados na 70ạ Assembleia Geral da ONU entre 25 e 27 de setembro de 2015 por mais 190 países, dando continuidade aos esforços internacionais das décadas de desenvolvimento anteriores, aperfeiçoando metas e indicadores propostos nos ODMs ao incluir uma nova gama de objetivos e metas, com maior 
ênfase na questão ambiental e social, em detrimento do caráter econômico. A nova agenda do desenvolvimento global para 2030 se baseou nos cinco P's: pessoas (erradicar a pobreza e a fome e garantir a dignidade e a igualdade); prosperidade (garantir vidas prósperas e plenas, em harmonia com a natureza); paz (promover sociedades pacíficas, justas e inclusivas); parcerias (implementar a agenda por meio de uma parceria global sólida); planeta (proteger os recursos naturais e o clima do nosso planeta para as gerações futuras). Estes cinco pontos organizam a visão de sustentabilidade e desenvolvimento que norteou o estabelecimento dos 17 ODSs (PNUD, 2016; Koehler, 2016).

Segundo Menezes e Minillo (2017), os Objetivos de Desenvolvimento do Milênio (ODM) e os Objetivos de Desenvolvimento Sustentável (ODS) constituem a maior iniciativa global organizada para a temática do desenvolvimento e suas múltiplas dimensões socioeconômicas. Os ODM e os ODS estabeleceram metas negociadas internacionalmente a serem alcançadas individualmente pelos países a partir de suas próprias iniciativas domésticas em suas diferentes esferas de governo, a sociedade civil e o setor privado de forma geral.

\section{Modelo de análise e resultados}

No início do trabalho perguntamos se há evidências empíricas da difusão de normas das organizações internacionais para o Brasil. Conforme exposto, assumimos uma posição que decorre do institucionalismo sociológico/organizacional segundo a qual as políticas públicas são impactadas pela atuação de Organizações Internacionais que definem e difundem normas, modelos de políticas e ideias que servirão de parâmetros para os tomadores de decisão balizarem suas posições, tendo em vista legitimar suas decisões e as políticas públicas que delas decorrem. Como vimos, o conceito contemporâneo de desenvolvimento sustentável surge no debate internacional na ONU entre os anos de 1970 e 1980 e se consolidada partir da Rio 92.

Tomamos como caso de estudo o Brasil, que sediou a Rio 92 e foi um dos signatários dos ODS em 2015. Como visto anteriormente, uma das formas de as Organizações Internacionais impactarem a política doméstica é por meio da disseminação discursiva (JAKOBI, 2009). Além 
disso, como apontam Cortell e Davis (2000), podemos analisar a saliência de uma norma internacional, como o desenvolvimento sustentável, a partir dos discursos das autoridades públicas.

Desenvolvemos o modelo de análise de conteúdo a partir da premissa de que que a importância de um determinado termo em um texto aumenta com a frequência de sua aparição, conforme entendimento de Bardin (2009). Como informado na introdução do artigo, operacionalizamos o modelo de análise a partir de análise de conteúdo dedutiva, com a definição das seguintes categorias: economia, política social, meio ambiente e sustentabilidade.

Nossa hipótese, de que é possível observar empiricamente o efeito da difusão de normas no legislativo brasileiro, parte da seguinte proposição: se os termos relativos à categoria "economia" co-ocorrem com os termos relativos à categoria "sustentabilidade", então teremos a dimensão sustentabilidade econômica, voltada para o entendimento tradicional de crescimento da economia; de maneira similar, se "social" co-ocorre com "sustentabilidade", então teremos a dimensão sustentabilidade social, voltada para direitos e políticas sociais; se "meio ambiente" co-ocorre com "sustentabilidade", então teremos sustentabilidade ambiental, relativa aos limites dos recursos naturais, conforme apresentado anteriormente.

Seguindo o disposto por Kelle (2015), a análise de co-ocorrências pode ser extremamente útil para examinarmos nossa hipótese de pesquisa, desde que observadas as seguintes limitações:

- O pré-requisito de teste independente exige que a hipótese não seja testada com o mesmo material empírico a partir do qual ela foi desenvolvida;

- As hipóteses devem ser empiricamente testáveis, o que significa que elas devem ser suficientemente precisas e tenham conteúdo empírico;

- Os códigos que são empregados para teste de hipótese devem denotar claramente fenômenos precisos de maneira confiável e estável.

Tendo isso em mente cabe notar: 1. O material empírico a partir do qual nossa hipótese foi gerada decorre da literatura sobre as origens do desenvolvimento sustentável, 
apresentada na terceira parte desse artigo, portanto, completamente distinta do material empírico analisado (os diários da Câmara dos Deputados do Brasil); 2. Nossa hipótese, proposta com base na proposição se e então (KELLE, 2015), é precisa suficiente para ser empiricamente testável; 3. Os códigos empregados na construção das categorias denotam de forma precisa os fenômenos de forma confiável e estável, conforme apresentado abaixo nos Gráfico 1 e 2.

Como foi apresentado anteriormente, desenvolvimento sustentável, em suas dimensões econômica, social e ambiental, é um termo deriva do debate internacional sobre desenvolvimento. A análise de co-ocorrência das dimensões de análise lança luz empírica sobre a difusão do termo do nível internacional para o nível nacional: sendo nossa hipótese válida, variações em uma ou mais dimensões serão observadas no período de realização das conferências.

Com o auxílio do software Atlas.ti, codificamos os 448 documentos dos diários da Câmara dos Deputados coletados na base do Congresso Nacional. Os diários da Câmara dos Deputados incluem toda a atividade legislativa como projetos de lei, discursos em plenário, atividade das comissões, etc. Consideramos assim que "discurso" diz respeito a todo esse material textual publicado pelo Congresso e que constitui o corpus da pesquisa. Cabe lembrar que na análise de conteúdo é necessário definirmos a unidade de registro e a unidade de contexto (BARDIN, 2009), noções que estão incluídas nas caixas de codificação automática do Atlas.ti. A unidade de registro utilizada foram as palavras relacionadas a cada uma das categorias mencionadas anteriormente. Por sua vez, a unidade de contexto,

[...] serve de unidade de compreensão para codificar a unidade de registro e corresponde ao segmento da mensagem, cujas dimensões (superiores às da unidade de registro) são ótimas para que se possa compreender a significação exata da unidade de registro. Esta pode, por exemplo, ser a frase para a palavra e o parágrafo para o tema (BARDIN, 2009, p. 137)

Utilizamos como unidade de contexto a sentença, ou seja, o texto que se encontra entre dois pontos finais. A análise de co-ocorrência implica contar a frequência em que um determinado código (unidade de registro) está presente na mesma unidade de contexto de outro. O uso de co-ocorrência inclui o contexto na análise, ajudando a eliminar "codificações 
espúrias". Definimos como referência a unidade de contexto da categoria sustentabilidade. Ou seja, o software contou quantas vezes os termos das demais categorias apareceram na unidade de contexto (na mesma frase) da sustentabilidade. Desta maneira, só foram contadas as vezes que, por exemplo, "meio ambiente" aparece na mesma frase que "sustentável".

Seguindo o modelo analítico proposto, a análise de conteúdo foi feita em dois momentos: o primeiro com a codificação absoluta das categorias: economia, política social, meioambiente e sustentabilidade nos documentos; o segundo momento com a análise de coocorrência, ou seja, as dimensões: sustentabilidade econômica, sustentabilidade social e sustentabilidade ambiental.

Passemos, então, à apresentação dos dados. Em um primeiro momento, apresentamos a codificação em termos absolutos, sumarizada nos Gráficos 1 e 2 abaixo:

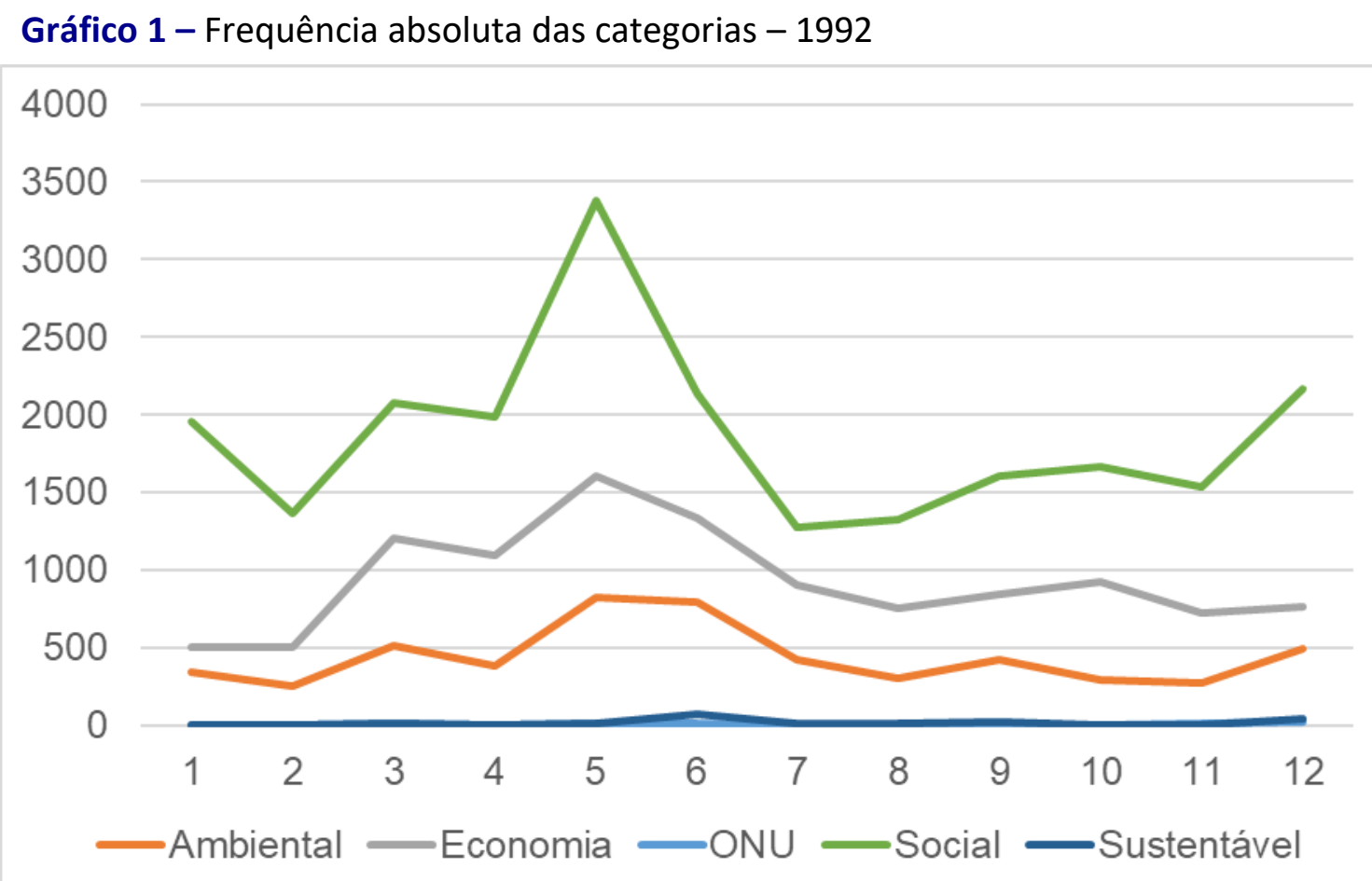

Fonte: os autores com dados da pesquisa.

O Gráfico 1 apresenta a frequência mensal da codificação absoluta das dos termos para o ano de 1992. O eixo $X$ apresenta os meses, enquanto que o Y o número total de registros feitos 
nos documentos a partir das categorias. No gráfico é possível notar um aumento expressivo na frequência das palavras pesquisadas e relacionadas à sustentabilidade no mês exatamente anterior à conferência da ONU no Rio de Janeiro, em que pese que aquele ano foi marcado pelo início do processo de impeachment do então presidente Fernando Collor. O gráfico também evidencia as prioridades da agenda pública brasileira tendo em vista as palavras que foram utilizadas na codificação dos documentos. Podemos notar que a agenda social é a mais relevante, seguida pela econômica e a ambiental. É possível verificar também que sustentabilidade era um termo ainda estranho, amplamente desconhecido e que surge com um pouco mais de ênfase justamente no mês de junho.

O Gráfico 2, abaixo, apresenta a codificação em termos absolutos das nossas categorias para o ano de 2015:

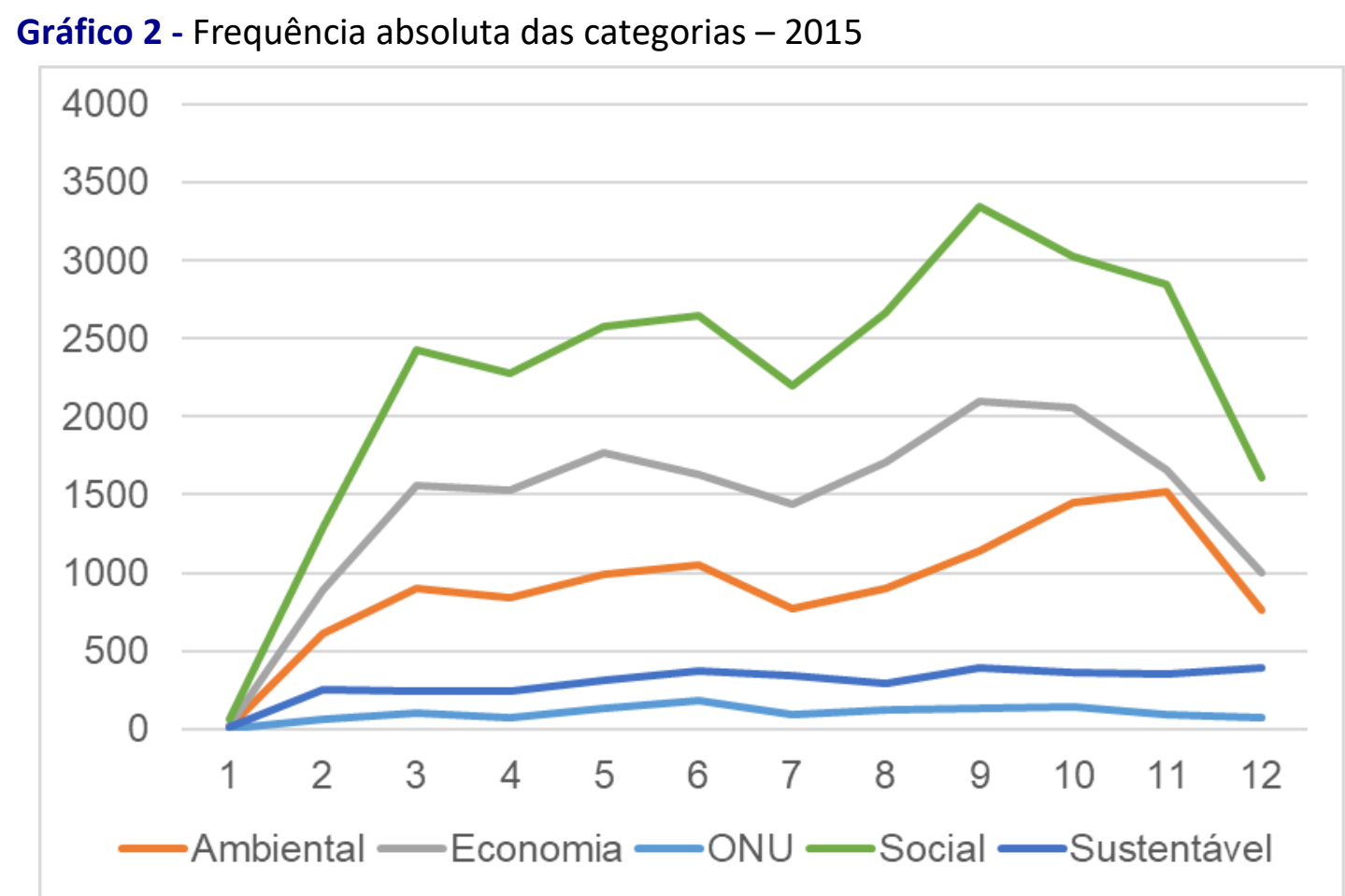

Fonte: os autores com dados da pesquisa.

A princípio, fica evidente a quase inexistência de atividade legislativa no mês de janeiro daquele ano. Comparado com o Gráfico 1, a ordem dos temas mais frequentes é a mesma, 
com o social com o maior número de registros, seguido de economia e meio ambiente. Notase, porém, que sustentabilidade passou a ser um termo mais frequente, apesar de sua frequência apresentar pouca variação ao longo do ano. Outro aspecto que chama a atenção é a maior frequência de todas as categorias em 2015 em relação à 1992, ou seja, os termos em nossas categorias foram mais citados em 2015 do que em 1992. De resto, é possível notar que todas as dimensões - ambiental, economia, social e sustentabilidade - foram utilizadas com maior frequência nas atividades da Câmara dos Deputados no mês de setembro, variando acima da média do restante do ano.

Apresentados os resultados brutos, a frequência da codificação absoluta das categorias, podemos passar para o segundo e mais relevante momento da análise de conteúdo da pesquisa, as co-ocorrências que definem as dimensões de análise nos gráficos 3 e 4.

Gráfico 3 - Análise de co-ocorrência para o ano de 1992

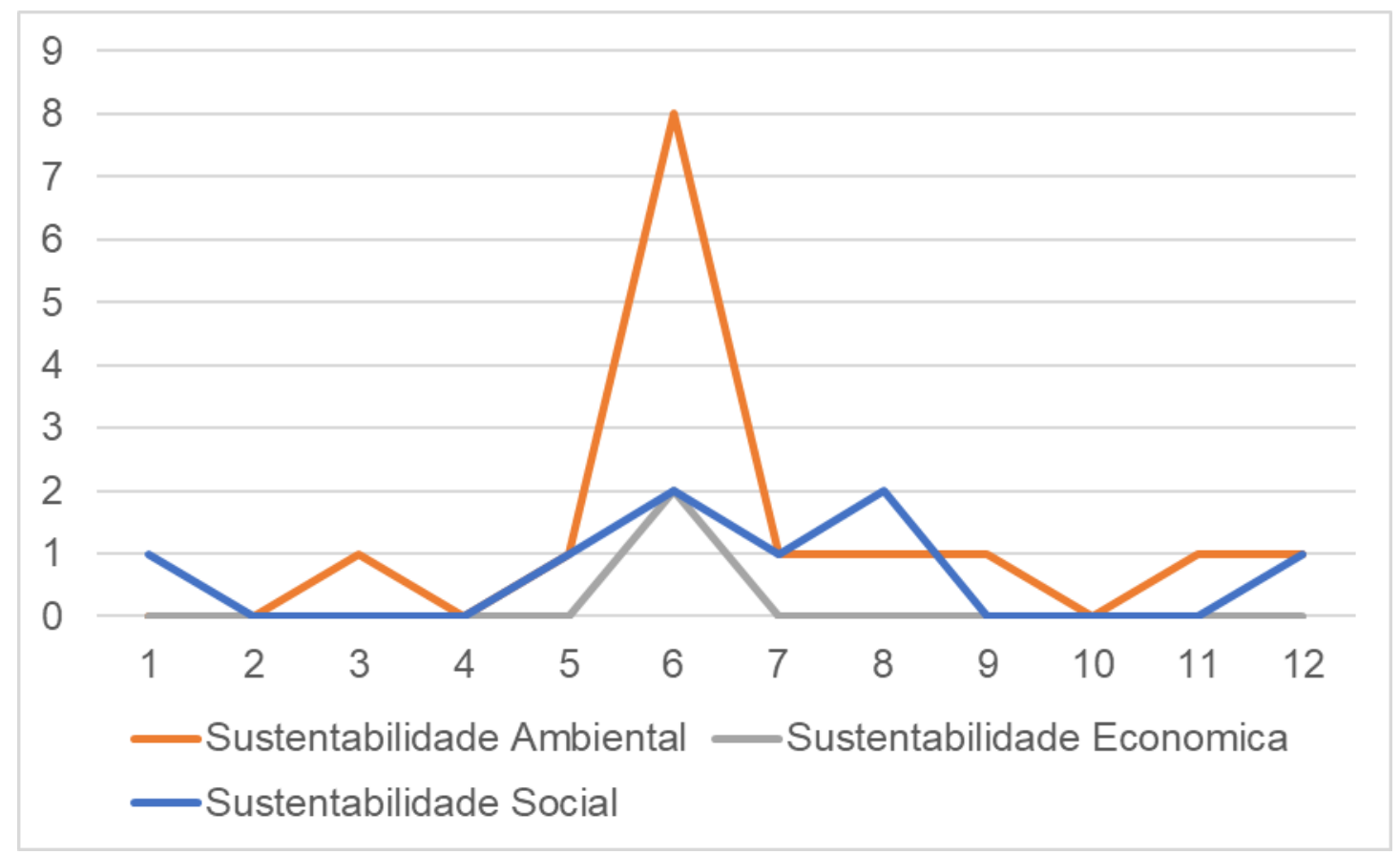

Fonte: os autores com dados da pesquisa.

Em primeiro lugar, cabe comparar os números do eixo y do Gráfico 3 com os do Gráfico 1. O uso da co-ocorrência dos termos reduz drasticamente o volume do material analisado. 
Realizada essa filtragem, com os dados do gráfico 3 podemos observar o impacto da conferência da ONU no trabalho da Câmara dos Deputados no mês de junho de 1992, com destaque para a dimensão ambiental da sustentabilidade (foco da conferência da Rio 92). A dimensão social, embora mais frequente na codificação absoluta, ficou em segundo lugar nas co-ocorrências com a dimensão sustentabilidade. A dimensão econômica foi a menos associada à sustentabilidade, sendo interessante notar que os termos só estiveram presentes na mesma frase no mês de junho. Cabe lembrar que, conforme apresentado no Gráfico 1, a categoria "sustentabilidade" demonstrou ser uma agenda distante da realidade legislativa, tendo aparecido somente 205 vezes ao longo do ano, contra 4996 vezes da ambiental, 10645 da economia e 20536 do social.

Gráfico 4 - Análise de co-ocorrência para o ano de 2015

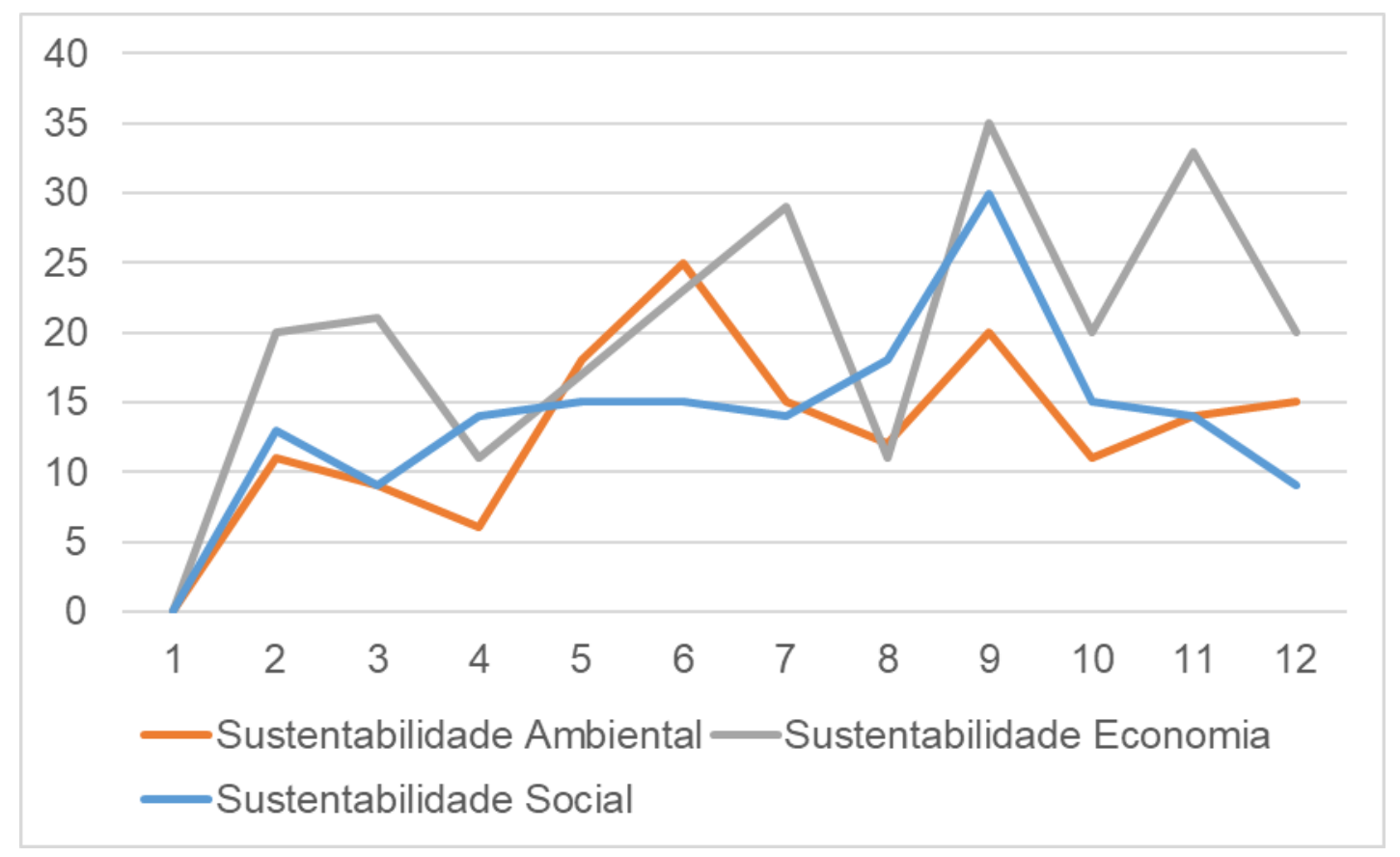

Fonte: os autores com dados da pesquisa.

Por fim, o Gráfico 4 apresenta os dados da análise de co-ocorrência para os dados de 2015. Três observações parecem mais pertinentes. Primeiramente, em termos absolutos, a categoria sustentável foi contada 3553 vezes ao longo do ano, contra 10929 vezes da categoria ambiental, 17345 da econômica e 26914 da social. Todas as categorias foram mais frequentes em 2015 de forma que a categoria ambiental cresceu certa de 2,2 vezes em 2015 comparado 
com 1992, a agenda econômica 1,6 e a social 1,3 vezes, respectivamente. Por outro lado, a categoria sustentabilidade passou a ser 17,3 vezes mais frequente em 2015 comparado com 1992. Em segundo lugar, é possível notar uma homogeneização dos dados, de forma que todas as três categorias, ambiental, economia e social, co-ocorrem com sustentabilidade ao longo de todo ao ano. Disso é possível inferir que não somente sustentabilidade se tornou um termo mais comum em 2015, mas também que sustentabilidade ambiental, econômica e social estavam muito mais difundidas. Em terceiro lugar, observa-se uma tendência de crescimento das dimensões econômica e social ao longo do ano de 2015, com particular destaque para a econômica.

\section{CONSIDERAÇÕES FINAIS}

O presente artigo analisou a relação entre políticas públicas e relações internacionais a partir dos constrangimentos cognitivos que as Ols criam para os tomadores de decisão domesticamente. Para tanto localizamos nosso trabalho nos estudos sobre difusão de normas internacionais, apresentamos a visão da literatura sobre o impacto das Ols e apresentamos a consolidação do desenvolvimento sustentável na agenda internacional. Em busca de elementos empíricos que sustentem as leituras realizadas, avaliamos como a difusão internacional de normas sobre desenvolvimento impactou o legislativo brasileiro em dois momentos chave para o debate internacional sobre desenvolvimento sustentável, em 1992 e em 2015.

Primeiramente, o modelo de análise desenvolvido se provou válido para o estudo proposto, tendo sido responsivo ao problema de pesquisa e à literatura pesquisada. Tomando como referência os gráficos apresentados na seção anterior, podemos inferir que: 1) o termo sustentabilidade se popularizou muito nos últimos tempos, em linha com o apontado na literatura; 2) a popularização do termo foi acompanhado de suas três dimensões - ambiental, social e econômica; 3) a dimensão econômica, no caso, desenvolvimento sustentável, demonstra a força da visão antropocêntrica apresentada anteriormente, com maior ênfase no desenvolvimento econômico e social. 
A principal conclusão do artigo, como apresentado na introdução, é que foi possível visualizar empiricamente a relação entre as discussões na ONU e o trabalho do legislativo no Brasil: no curto prazo, no ano de 1992 quando a dimensão sustentabilidade ambiental ecoou nos trabalhos da Câmara dos Deputados; no longo prazo, no ano de 2015 quando todas as dimensões analisadas refletiam a consolidação do debate internacional sobre desenvolvimento. Em termos gerais, o artigo corrobora a literatura sobre: difusão de normas; sobre o papel das Ols na difusão de determinadas normas; sobre o papel das Ols sobre as políticas públicas domesticamente. Isso implica que ideias produzidas no âmbito das Organizações Internacionais são difundidas globalmente e "normalizam" determinados conceitos que, por sua vez, passam a integrar o cotidiano dos tomadores de decisão e dos responsáveis pela elaboração das políticas públicas, e que as ideias que esses atores têm sobre os problemas e as soluções são gradualmente transformadas, e as novas noções, no caso, desenvolvimento sustentável, passam a legitimar novas decisões.

Como limitações e apontamentos para pesquisas futuras cabe registrar que, embora a metodologia empregada, em particular a análise de co-ocorrência, permita visualizar o impacto da ONU no trabalho do legislativo brasileiro e analisar a hipótese do trabalho, a análise de frequência é insuficiente para uma conclusão mais assertiva. Eventualmente, um desenho de pesquisa quali/quantitativo, que permita teste de hipótese, possibilite um controle maior dos resultados, mesmo que em termos estatísticos. Em relação a pesquisas futuras, inicialmente cabe ressaltar a enorme riqueza da base de dados analisada. Os diários do legislativo são uma fonte primária riquíssima e detalhada da história política do Brasil. Nesse sentido, trabalhos que dissequem cada um dos 17 ODS e avancem na metodologia podem contribuir significativamente para avançar a literatura sobre difusão.

\section{REFERÊNCIAS}

BARDIN, L. Análise de conteúdo. rev. e atual. Lisboa: Edições, v. 70, n. 3, 2009.

BENNETT, C. J. What Is Policy Convergence and What Causes It? British Journal of Political Science, v. 21, n. 2, p. 215-233, 1991. 
BENNETT, C. J.; HOWLETT, M. The Lessons of Learning: Reconciling Theories of Policy Learning and Policy Change. Policy Sciences, v. 25, n. 3, p. 275-294, 1992.

BENSON, D.; JORDAN, A. What have we Learned from Policy Transfer Research? Dolowitz and Marsh Revisited. Political Studies Review, v. 9, n. 3, p. 366-378, set. 2011.

BRUNDTLAND, G. H. et al. Our common future. New York, v. 8, 1987.

DOBBIN, F.; SIMMONS, B.; GARRETT, G. The Global Diffusion of Public Policies: Social Construction, Coercion, Competition, or Learning? Annual Review of Sociology, v. 33, n. 1, p. 449-472, ago. 2007.

DOLOWITZ, D. P.; MARSH, D. Learning from Abroad: The Role of Policy Transfer in Contemporary Policy-Making. Governance, v. 13, n. 1, p. 5-23, jan. 2000.

FARIA, C. A. P. DE. Idéias, conhecimento e políticas públicas: um inventário sucinto das principais vertentes analíticas recentes. Revista Brasileira de Ciências Sociais, v. 18, n. 51, fev. 2003.

FARIA, C. A. P. DE. Políticas públicas e relações internacionais. 2018.

FINNEMORE, M. Norms, Culture, and World Politics: Insights from Sociology's Institutionalism. International Organization, v. 50, n. 2, p. 325-347, 1996.

FINNEMORE, M.; SIKKINK, K. International Norm Dynamics and Political Change. International Organization, v. 52, n. 4, p. 887-917, 1998.

GIDDENS, A. Problemas Centrais Em Teoria Social: ação, estrutura e contradição na análise sociológia. [s.I.] VOZES, 2018.

GILARDI, F. Transnational Diffusion: Norms, Ideas, and Policies. In: Handbook of International Relations. 1 Oliver's Yard, 55 City Road, London EC1Y 1SP United Kingdom: SAGE Publications Ltd, 2013. p. 453-477.

GRAHAM, E. R.; SHIPAN, C. R.; VOLDEN, C. The Diffusion of Policy Diffusion Research in Political Science. British Journal of Political Science, v. 43, n. 3, p. 673-701, jul. 2013.

GROBER, $U$. The discovery of sustainability: The genealogy of a term. In: Theories of sustainable development. [s.l.] Routledge, 2014. p. 16-25.

JAKOBI, A. P. Global education policy in the making: International organisations and lifelong learning. Globalisation, Societies and Education, v. 7, n. 4, p. 473-487, 2009.

JANNUZZI, P. M.; DE CARLO, S. Da agenda de desenvolvimento do milênio ao desenvolvimento sustentável: oportunidades e desafios para planejamento e políticas públicas no século XXI. Bahia Análise \& Dados, v. 28, n. 2, p. 6-27, 2019. 
KANIE, N. et al. Integration and Diffusion in Sustainable Development Goals: Learning from the Past, Looking into the Future. Sustainability, v. 6, n. 4, p. 1761-1775, 3 abr. 2014.

KELLE, U. Análise com auxílio de computador: codificação e indexação. In: Pesquisa qualitativa com texto, imagem e som: um manual prático. 13. ed. Petrópolis: Vozes, 2015.

KINGDON, John, W. Agendas, Alternatives and Public Policies. Essex, Pearson Education Limited. $2^{\text {nd }}$ Edition. 2014

LANDOLT, L. K. Review: (Mis)Constructing the Third World? Constructivist Analysis of Norm Diffusion Reviewed Work(s): National Interests in International Society by Martha Finnemore; Activists beyond Borders by Margaret Keck and Kathryn Sikkink; The Power of Human Rights: International Norms and Domestic Change by Thomas Risse, Stephen C. Ropp and Kathryn Sikkink. Third World Quarterly, v. 25, n. 3, p. 579-591, 2004.

MARSH, D.; SHARMAN, J. C. Policy diffusion and policy transfer. Policy Studies, v. 30, n. 3, p. 269-288, jun. 2009.

MEYER, J. W.; ROWAN, B. Institutionalized Organizations: Formal Structure as Myth and Ceremony. American Journal of Sociology, v. 83, n. 2, p. 340-363, set. 1977.

PATERSON, M. Green politics. Theories of international relations, v. 2, 2001.

ROBINSON, J. Squaring the circle? Some thoughts on the idea of sustainable development. Ecological Economics, v. 48, n. 4, p. 369-384, 20 abr. 2004.

SANTOS-FILHO, Onofre. O Fogo de Prometeu nas mãos de Midas: desenvolvimento e mudança social In: LAS CASAS CAMPOS, Taiane (Org.). Desenvolvimento, desigualdades e relações Internacionais. Belo Horizonte: Ed. PUC Minas, 2005. p. 13-75 